\title{
HEALTH VISITORS
}

Health visitors do far more than monitor the health of young children, explains Andrew Cole.

\section{USEFUL INFORMATION}

Health Visitors'

Association

50 Southwark Street London SE1 1UN

Tel: 01713787255

United Kingdom Central Council for Nursing, Midwifery and Health Visiting

23 Portland Place London W1N 3AF

Tel: 01716377181
$\mathbf{T}$ here are around 20,000 health visitors. All will have trained first to be a registered nurse, and many will be midwives as well. They complete a further one-year training to qualify as a health visitor.

Like nurses and midwives, every practising health visitor is answerable to their professional body, the United Kingdom Central Council for Nursing, Midwifery and Health Visiting (UKCC), which is responsible for standards in education, professional regulation and the protection of the public.

Health visitors often work in multidisciplinary teams, alongside practice nurses, district nurses, social workers, midwives and GPs. They are employed by the NHS and can work from a GP practice, a health centre or a local clinic. They are usually responsible for between 250 and 500 families at any one time.

The health visitor's principal role is health promotion, and monitoring the health of children under five is one of the main aspects of this. It can range from giving advice on breastfeeding and immunisation to checking that the child is developing normally.

Increasingly, however, health visitors are taking on a much wider health promotion and counselling role with families, single people and older people. They also play an important part in assessing the health needs of the local population and in 'outreach' work with those in danger of falling through the health net, such as the homeless, travellers and drug abusers. In addition, they perform a vital monitoring service, checking for signs of potential child (or elder) abuse in the home, as well as providing advice on day-to-day requirements - for example, benefits and translation services.

Some specialist health visitors now work with children with longterm disabilities and behavioural problems.

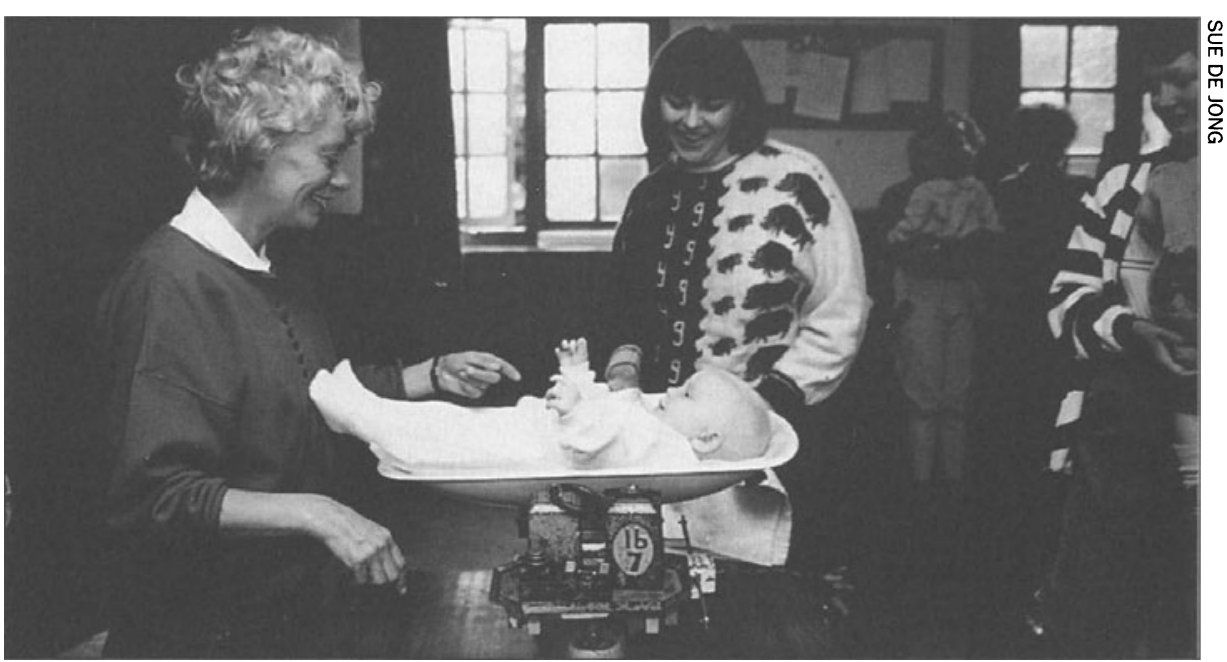

Health visitors check the weight and health of under-fives. 